\title{
Ameliorating Effects of Short-Chain Inulin-Like Fructans on the Healing Stage of Trinitrobenzene Sulfonic Acid-Induced Colitis in Rats
}

\author{
Shingo Hino, ${ }^{1}$ Hiroyuki Ito, ${ }^{1}$ Hiroyuki Bito, ${ }^{1}$ Hirokazu Kawagishi,${ }^{2}$ and Tatsuya Morita ${ }^{1, \dagger}$ \\ ${ }^{1}$ Department of Applied Biological Chemistry, Faculty of Agriculture, Shizuoka University, \\ 836 Ohya, Shizuoka 422-8529, Japan \\ ${ }^{2}$ Graduate School of Science and Technology, Shizuoka University, 836 Ohya, Shizuoka 422-8529, Japan
}

Received June 15, 2011; Accepted August 4, 2011; Online Publication, November 7, 2011

[doi:10.1271/bbb.110460]

We evaluated the ameliorating effects of short-chain inulin-like fructans (SIF) with different degrees of polymerization (DP) on the healing stage of trinitrobenzene sulfonic acid (TNBS)-induced colitis in rats. The rats were assigned to 3 groups $10 \mathrm{~d}$ after the colitis induction, and fed for $24 \mathrm{~d}$ on a control diet or diet including $60 \mathrm{~g}$ of DP4 or DP8/kg. The fecal myeloperoxidase (MPO) activity and IgA concentration were monitored every $7 \mathrm{~d}$. The colonic MPO activities and cecal concentrations of organic acids, lactobacilli, bifidobacteria, mucin and IgA were measured at the end of the study. DP4, but not DP8, significantly reduced the colonic inflammation accompanied by higher cecal concentrations of short-chain fatty acids, propionate in particular, and lactic acid-producing bacteria. DP4 therefore accelerated the healing process of TNBSinduced colitis, even when the treatment was initiated after inducing colitis.

Key words: short-chain inulin-like fructans; short-chain fatty acids; lactobacilli; trinitrobenzene sulfonic acid (TNBS) colitis; rats

Inflammatory bowel disease is a chronic disease of the digestive tract and usually refers to two related conditions, ulcerative colitis and Crohn's disease, characterized by spontaneously relapsing inflammation. The etiology of inflammatory bowel disease remains unclear, but it is believed that genetic, immunologic and colonic environmental factors, including microbiota, may be involved. ${ }^{1)}$ Diet is a major factor affecting the luminal environment and intestinal immune function. ${ }^{2)}$ Considerable attention has recently been paid to prebiotic and probiotic treatments which aim to stimulate the growth of lactic acid-producing bacteria, reduce colonic $\mathrm{pH}$, and maintain mucosal integrity by augmenting the production of colonic short-chain fatty acids (SCFAs). ${ }^{3-6)}$ Prebiotic and probiotic treatments also have the potential to increase both luminal mucin and $\operatorname{IgA}$ that are related to the mucosal barrier function against bacteria and endotoxin translocation. ${ }^{7,8)}$

We have previously shown that pre-treating shortchain inulin-like fructans (SIF), with average degrees of polymerization (DP) of 4 (virtually the same as fructooligosaccharides) and 8, exerted preventive effects on the acute phase of trinitrobenzene sulfonic acid (TNBS)-induced colitis in rats. ${ }^{7)}$ SIF, and DP8 in particular, increased the cecal concentrations of SCFA, mucin and $\operatorname{IgA}$ before the induction of colitis, and reduced bacterial and endotoxin translocation to the mesenteric lymph node and portal blood $3 \mathrm{~d}$ after the TNBS administration. However, these beneficial effects of DP4 and DP8 on the cecal valuables were abolished $10 \mathrm{~d}$ after the TNBS administration, despite the significant reduction of colonic inflammation. We therefore assumed that these anti-inflammatory effects of SIF might be exerted through a shield-like effect against endotoxin and bacterial translocation at the early stage of colitis, leading to the reduced colonic damage $10 \mathrm{~d}$ after the induction of colitis. ${ }^{7)}$

A number of studies examining the effects of prebiotics, including dietary fiber and probiotics, on TNBSinduced rat colitis have already been reported, but most of them evaluated the preventive effects in the acute phase of colitis within 1-2 weeks after TNBS administration; ${ }^{5,6,9-12)}$ the outcome was mostly successful when the treatment began before the induction of colitis. Indeed, Peran et $a l .{ }^{6}$ ) have reported for rats that a pretreatment of Lactobacillus rutei and L. fermentum, starting 2 weeks before TNBS administration, significantly reduced colonic damage both histologically and biochemically. However, Kennedy et al. ${ }^{13)}$ have shown that probiotic Lactobacillus plantarum species 299 and oat fiber had no effect on colonic inflammation when given for $7 \mathrm{~d}$ following TNBS administration. This was probably because the inflammation in the acute phase of TNBS colitis was so extensive and severe due to the caustic properties of TNBS and ethanol, ${ }^{14}$ besides the hapten-induced immunological modulation. ${ }^{15)}$ Even chemotherapy, using an inhibitor of neutrophil activation $^{16)}$ and dexamethazone, ${ }^{17}$ did not produce any significant effects when the treatment was initiated after the induction of colitis. Taken together, it is likely that, apart from the preventive effect, the acute phase of TNBS colitis is not suitable for examining any beneficial (therapeutic) effects of dietary factors.

It has been well established that the rat TNBS colitis model induced long-lasting colitis for at least 6 weeks after its induction, although the colonic inflammation gradually healed and damage scores decreased from its

$\dagger$ To whom correspondence should be addressed. Tel/Fax: + 81-54-238-5132; E-mail: atmorit@ipc.shizuoka.ac.jp

Abbreviations: $\alpha 1$-AG, $\alpha 1$-acid glycoprotein; DP, degree of polymerization; MPO, myeloperoxidase activity; SCFA, short-chain fatty acid; SIF, short-chain inulin-like fructans; TNBS, trinitrobenzene sulfonic acid 
inflammatory peak $7 \mathrm{~d}$ after the induction. ${ }^{14,18)}$ This may permit us to study the influence of dietary factors during the healing stage of colitis. The present study was accordingly aimed to examine whether the effects of SIF could accelerate the healing process of TNBS colitis in rats. Once colitis had been established, the rats were assigned to each dietary group on the basis of the severity of colonic inflammation as assessed by the fecal myeloperoxidase activity (MPO). The dietary treatment was started $10 \mathrm{~d}$ after the induction of colitis and continued for $24 \mathrm{~d}$.

\section{Materials and Methods}

Materials. SIF with DP4 and DP8 were used. Meioligo ${ }^{\circledR}$ P DP4 was purchased from Meiji Seika (Tokyo, Japan), its composition being $44 \%$ of 1-kestose, $46 \%$ of nystose, and $10 \%$ of 1-f- $\beta$-fructofuranosyl nystose. DP8 (with a 5-13 range of DP) was prepared by enzymatic synthesis, using a novel fungal enzyme $\beta$-fructosidase from bacillus $\mathrm{sp}$. 217C-11, as described previously. ${ }^{7,19)}$

Care of the animals. Male Sprague-Dawley rats (SPF) were purchased from Shizuoka Laboratory Animal Center (Hamamatsu, Japan). They were housed in individual screen-bottomed stainless steel cages in a room with controlled temperature $\left(23 \pm 2{ }^{\circ} \mathrm{C}\right)$ and lighting (lights on from 8:00 to 20:00). The rats were fed with a control diet for at least $3 \mathrm{~d}$ for adaptation which was formulated from $250 \mathrm{~g} / \mathrm{kg}$ of casein, $652.25 \mathrm{~g} / \mathrm{kg}$ of cornstarch, and $50 \mathrm{~g} / \mathrm{kg}$ of corn oil. ${ }^{19)}$ The remainder of the diet consisted of vitamins and minerals (AIN-76). ${ }^{20}$ ) The body weight and food intake were recorded every morning before replenishing the diet. The study was approved by the Animal Use Committee of Shizuoka University, the animals being maintained in accordance with the guidelines of Shizuoka University for the care and use of laboratory animals.

Comparison between fecal MPO and plasma $\alpha 1$-acid glycoprotein $(\alpha 1-A G)$ as non-invasive inflammation markers (preliminary experiment). Thirteen rats (251-278 g, 8 weeks old) were used. After feeding the control diet for $7 \mathrm{~d}$, the rats were lightly anesthetized with diethyl ether and then treated with an intracolonic injection of a $20 \%$ glycerin solution $(0.2 \mathrm{~mL} / \mathrm{rat})$, using a lubricated polypropylene catheter $(1.5 \mathrm{~mm}$ diameter) inserted $8 \mathrm{~cm}$ into the colon via the anus. Preliminary results indicated that this treatment was useful for removing the colonic contents. Defecation was usually completed within $15 \mathrm{~min}$, and the colon was kept empty for at least $60 \mathrm{~min}$ after the treatment. At $60 \mathrm{~min}$ after administering the glycerin solution, 8 rats were anesthetized by diethyl ether and similarly given $30 \mathrm{mg}$ of TNBS dissolved in $0.25 \mathrm{~mL}$ of $50 \%$ ethanol $(\mathrm{v} / \mathrm{v})$ by a polypropylene catheter inserted $8 \mathrm{~cm}$ through the anus. Another 5 rats received saline as a control. Feces were collected 7-8 d after the TNBS administration and used for measuring the fecal MPO activity. The rats were then anesthetized with diethyl ether $8 \mathrm{~d}$ after the instillation, and the colon and blood were collected. The colon was cut open longitudinally and the colonic contents removed. The colonic tissue was stored at $-80{ }^{\circ} \mathrm{C}$ pending measurement of the MPO activity. The blood sample was obtained from the abdominal aorta with a heparinized syringe. The plasma was then obtained, after centrifugation at $2000 \times g$ for $10 \mathrm{~min}$ at $4{ }^{\circ} \mathrm{C}$, and used for measuring $\alpha 1-\mathrm{AG}$.

Ameliorating effects on the healing stage of TNBS-induced colitis by SIF ingestion. Thirty-five rats (207-237 g, 7 weeks old) were used. After feeding the control diet for $7 \mathrm{~d}$, the rats were administered with $20 \%$ glycerin and then TNBS $/ 50 \%$ ethanol in the same manner as that used in preliminary experiment 1 . The feces were collected $6-9 \mathrm{~d}$ after instillation and measured for MPO activity (6-7 d) and IgA concentration (8-9 d). The rats were then allocated to 3 groups on the basis of the fecal MPO activities, and allowed free access for $24 \mathrm{~d}$ to the control diet, the diet containing $60 \mathrm{~g}$ of DP4 $/ \mathrm{kg}$ of diet or the diet containing $60 \mathrm{~g}$ of DP8 $/ \mathrm{kg}$ of diet. Each of the test fructans was substituted by the same amount of cornstarch as that in the control diet (control, $n=15$; DP4 and DP8, $n=10$ ). The feces were collected every $7 \mathrm{~d}$ and measured for the MPO activity and IgA concentration. The rats were anesthetized with diethyl ether at the end of test period, and the cecum and the colon were excised. The cecal contents were removed, weighed, and divided into two portions. One was freeze-dried and used for a mucin analysis, and the other was used for measuring the $\mathrm{pH}$ value, organic acids, IgA, bifidobacteria and lactobacilli. The colon was handled in the same manner as that described for the preliminary experiment.

MPO activity. The colonic MPO activity was determined as previously described. ${ }^{7)}$ Briefly, the colon was minced and homogenized by a Polytron device in a $50 \mathrm{~mm}$ potassium phosphate buffer ( $\mathrm{pH}$ 6.0) containing $0.5 \%$ hexadecyltrimethyl ammonium bromide. The resulting homogenate was subjected to three cycles of freezethawing and sonication, and then centrifuged at $20,000 \times g$ for $30 \mathrm{~min}$. The feces were handled in the same manner as that described for the colonic tissue, but without freeze-thawing and sonication. The supernatants of the colonic and fecal homogenates were used to determine the MPO activity, using $0.0005 \%$ hydrogen peroxide as the substrate for MPO. One unit of MPO activity is defined as that converting $1 \mu \mathrm{mol}$ of hydrogen peroxide to water per $1 \mathrm{~min}$ at $25^{\circ} \mathrm{C}$.

Plasma $\alpha 1-A G$. Plasma $\alpha 1-\mathrm{AG}$ was analyzed by an $\alpha$-1-acid glycoprotein rat ELISA kit (Life Diagnostics, PA, USA) according to manufacturer's instructions.

Cecal pH and organic acids. After the cecal contents had been homogenized, a portion of the homogenate was diluted with the same weight of distilled water, and then the cecal $\mathrm{pH}$ value was measured with a C-1 compact $\mathrm{pH}$ meter (Horiba, Tokyo, Japan). The cecal organic acids were measured by the internal standard method ${ }^{21)}$ with an LC-10A HPLC instrument (Shimadzu, Kyoto, Japan) equipped with a Shim-pack SCR-102H column $(8 \mathrm{~mm}$ i.d. $\times 30 \mathrm{~cm}$ long, Shimadzu) and a CDD-6A electro-conductivity detector (Shimadzu).

Secretory IgA. The feces and cecal contents were homogenized with a 10-fold volume of phosphate-buffered saline (PBS, pH 7.4) containing Complete protease inhibitors (Roche, Basel, Switzerland) for feces and $0.02 \mathrm{M}$ sodium azide and $0.5 \%$ Tween 20 for the cecal contents. Each of these homogenates was centrifuged at $15,000 \times g$, and the resulting supernatant was applied to an IgA determination by ELISA, using Nunc-Immuno MaxiSorb F96 plates with a small modification ${ }^{22)}$ of the method described by Grewal et al. ${ }^{23)}$ Each assay was conducted in duplicate.

O-Linked oligosaccharide chains. Mucins were extracted by the method of Bovee-Oudenhoven et al. ${ }^{24)}$ with some modifications. ${ }^{19)}$ The $O$-linked oligosaccharide chains were determined as a mucin marker. After appropriately diluting the mucin fraction, the $O$-linked oligosaccharide chains were measured with a fluorimetric assay ${ }^{25)}$ that discriminated $O$-linked glycoproteins (mucin) from $\mathrm{N}$-linked glycoproteins, as described by Bovee-Oudenhoven et al. ${ }^{24)}$ Standard solutions of $\mathrm{N}$-acetyl galactosamine (Sigma, St. Louis, MO, USA) were used to calculate the quantity of oligosaccharide chains liberated from mucins during the procedure.

Isolation of bacterial DNA. A $50 \mathrm{mg}$ amount of the cecal contents

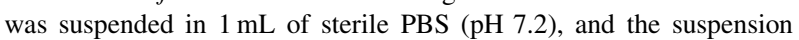
centrifuged at $700 \times g$ for $1 \mathrm{~min}$. The supernatant was collected and re-centrifuged at $10,000 \times g$ for 10 min to yield the bacterial fraction. Bacterial DNA was isolated from this fraction by Isoplant (Nippon Gene, Tokyo, Japan) according to manufacturer's instructions. The concentration and purity of the bacterial DNA were estimated by measuring its $\mathrm{OD}_{260 / 280}$ value.

Real-time PCR for bifidobacteria and lactobacilli. Amplification and detection of the bacterial DNA were performed with an ST-300 Light Cycler (Roche). Bifidobacterium genus-specific (forward, TCG CGT C(C/T)G GTG TGA AAG; reverse, CCA CAT CCA GC(A/G) TCC AC) ${ }^{26)}$ and Lactobacillus genus-specific (forward, TGG AAA CAG (A/G)TG CTA ATA CCG; reverse, GTC CAT TGT GGA AGA TTC CC $)^{27)}$ primer pairs were used. Real-time PCR was performed in a reaction volume of $20 \mu \mathrm{L}$, the mixture containing $10 \mu \mathrm{L}$ of SYBR 
a

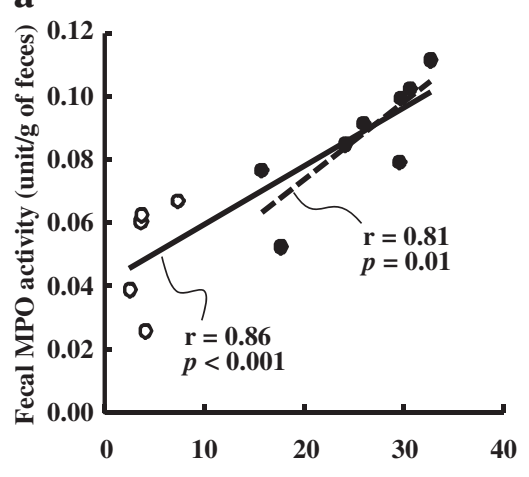

Colonic MPO activity (unit/g of tissue) b

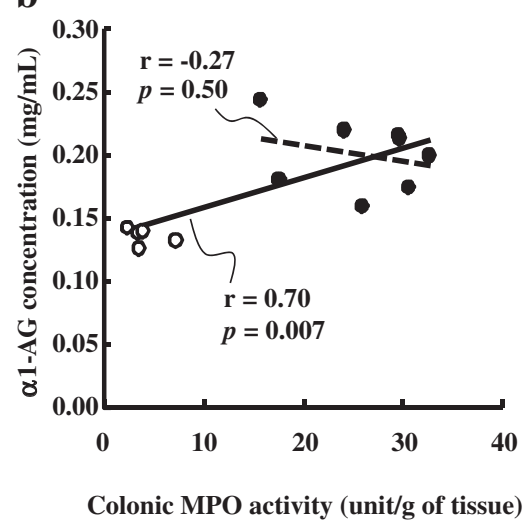

Fig. 1. Correlation of the Colonic MPO Activity with the Fecal MPO Activity (a) and the Plasma $\alpha 1$-Acid Glycoprotein Concentration (b) in Rats by $8 \mathrm{~d}$ after TNBS Administration.

Solid lines incorporate all of the data. Broken lines omit data from the normal rats.

TNBS-treated rats; $\bigcirc$, normal rats.

Premix Ex Taq II (Takara Bio, Tokyo, Japan), $0.8 \mu \mathrm{L}$ of $200 \mathrm{~nm}$ each of the forward and reverse primers, $6.4 \mu \mathrm{L}$ of $\mathrm{H}_{2} \mathrm{O}$ and $2 \mu \mathrm{L}$ of the bacterial DNA templates. The reaction conditions were $95^{\circ} \mathrm{C}$ for $30 \mathrm{~s}$, then 43 cycles at $95^{\circ} \mathrm{C}$ for $5 \mathrm{~s}$ and $64^{\circ} \mathrm{C}$ for $30 \mathrm{~s}$ for quantifying the bifidobacteria, and $95^{\circ} \mathrm{C}$ for $30 \mathrm{~s}$, then 43 cycles at $95^{\circ} \mathrm{C}$ for $5 \mathrm{~s}$ and $65^{\circ} \mathrm{C}$ for $30 \mathrm{~s}$ for quantifying the lactobacilli. The amplification specificity was confirmed by subjecting the PCR products to a melting curve analysis. Bifidobacterium animalis $\left(\mathrm{JCM} 1190^{\mathrm{T}}\right.$ ) and Lactobacillus murinus (JCM $1717^{\mathrm{T}}$ ) were cultured in De Man, Rogosa and Sharpe broth (Becton Dickinson, Rockville, MD, USA), and genomic DNA was extracted by Isoplant-II (Nippon Gene) according to the manufacturer's instructions. Fragments of 16S rDNA were amplified by PCR with the Bifidobacterium or Lactobacillus genus-specific primer pairs already described. The amplicons were purified by a GFXe PCR DNA and Gel Band Purification kit (GE Healthcare Bioscience, Tokyo, Japan) and cloned in pGEMEasy $\mathrm{T}$ vectors (Promega, Madison, WI, USA). Transformation was performed with competent Escherichia coli XL-1 Blue cells and plated on to LuriaBertani agar plates supplemented with ampicillin $(25 \mu \mathrm{g} / \mathrm{mL}), X-G a l$ $(30 \mathrm{mg} / \mathrm{mL})$ and isopropyl $\beta$-D-1-thiogalactopyranoside $(20 \mu \mathrm{g} / \mathrm{mL})$, the plates being incubated overnight at $37^{\circ} \mathrm{C}$. The white transformants were picked out and grown in Luria-Bertani broth. Plasmid DNA was extracted with a QIAprep Spin Miniprep kit (Qiagen, Germantown, $\mathrm{MD}$, USA) and used as a standard for real-time PCR.

Statistical analyses. Data were analyzed by one-way ANOVA, significant differences among means being identified by a TukeyKramer test. The data were logarithmically transformed when the variance was not homogenous by the Bartlett test. If the variance was still not homogenous after logarithmic transformation, the data were presented as medians with range, and then analyzed by Kruskal-Wallis ANOVA with a subsequent Kolmogorov-Smirnov 2-sample test. The statistical calculations were carried out by Stat View 5.0 software (SAS Institute). Regression analyses were performed with the Stat Cel 2 program (Tokyo Shoseki), $n$ being at the level of an individual rat when correlation coefficients were calculated.

\section{Results}

Fecal MPO and plasma $\alpha 1-A G$ as non-invasive inflammation markers (preliminary experiment)

The average body weight of the rats was $295 \pm 3 \mathrm{~g}$ just before the TNBS administration. The respective food intake and body weight gain were $156 \pm 5 \mathrm{~g} / 8 \mathrm{~d}$ and $40 \pm 3 \mathrm{~g} / 8 \mathrm{~d}$ for the normal rats, and $107 \pm 4 \mathrm{~g} / 8 \mathrm{~d}$ and $11 \pm 3 \mathrm{~g} / 8 \mathrm{~d}$ for the TNBS-administered rats. The colonic MPO activities were about 6-fold higher in the TNBS-administered rats than in the normal rats (normal, $4.2 \pm 0.8 ;$ TNBS, $25.2 \pm 3.5$ unit/g of tissue). Both the fecal MPO activity (normal, $0.05 \pm 0.01$; TNBS,
$0.09 \pm 0.01 \mathrm{unit} / \mathrm{g}$ of feces) and the plasma $\alpha 1-\mathrm{AG}$ concentration (normal, $0.14 \pm 0.00$; TNBS, $0.20 \pm 0.01$ $\mathrm{mg} / \mathrm{mL}$ ) were also significantly higher in the TNBSadministered rats than in the normal rats. The correlations between the colonic MPO activity and both the fecal MPO activity and plasma $\alpha 1-\mathrm{AG}$ concentration were significant (Fig. 1a and b). However, higher correlation was apparent between the fecal MPO activity and colonic MPO activity. Even if the data from normal rats are omitted, significant correlation was apparent between the fecal MPO activity and colonic MPO activity with a correlation coefficient of 0.81 .

Ameliorating effects of SIF ingestion on the healing stage of TNBS-induced colitis

The average body weight of the rats just before the TNBS administration was $278 \pm 2 \mathrm{~g}$. The food intake and body weight decreased sharply for the first few days after the TNBS administration and then gradually recovered in the following days. The average body weight of the rats was $286 \pm 3 \mathrm{~g}$ before the dietary treatment. The food intake was significantly lower during the dietary treatment by the rats fed with the DP4 and DP8 diets than by those fed the control diet (control, $487 \pm$ 9; DP4, $444 \pm$ 9; DP8, $387 \pm 13 \mathrm{~g} / 24 \mathrm{~d}$ ), although significant differences in the body weight gain were only apparent between the DP8 and control diet groups (control, $113 \pm 2$; DP4, $103 \pm 5$; DP8, $75 \pm 7 \mathrm{~g}$ / $24 \mathrm{~d}$; Fig. 2a and b). Soft unformed feces were observed during the initial few days from the rats fed with the DP4 and DP8 diets.

At the start of the dietary treatment (d 0), the average fecal MPO activity among the rats was $0.9 \pm 0.3$ unit $/ g$ of feces. The fecal MPO activity in the rats fed the DP4 diet was increased by $\mathrm{d} 7$, then decreased to the same level as that in the control group by $\mathrm{d} 14$, and remained constant until the end of the test period (Fig. 3a). The fecal MPO activity in the rats fed the DP8 diet was significantly higher than in those fed the control diet by $\mathrm{d} 7$ and $\mathrm{d} \mathrm{14}$, and was comparable with those on the control diet by $\mathrm{d} 21$. The fecal IgA concentration was significantly higher in the rats fed the DP4 and DP8 diets than in those fed the control diet by $\mathrm{d} 7$ (Fig. 3b).

The autopsy showed no ulcer and bleeding when macroscopically observed in the colonic mucosa of all 
a

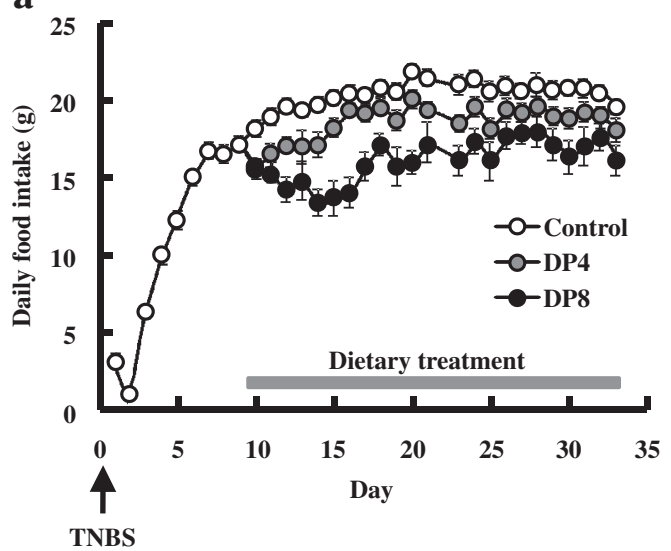

b

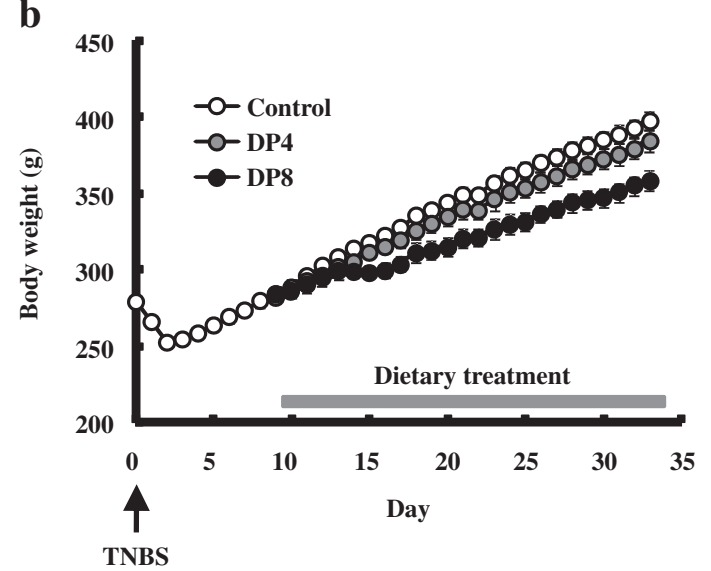

Fig. 2. Daily Food Intake (a) and Change in Body Weight (b) of Rats after the TNBS Administration.

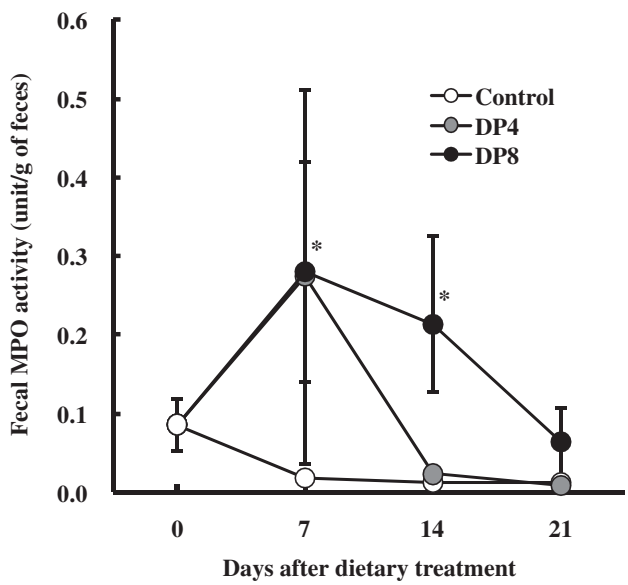

b

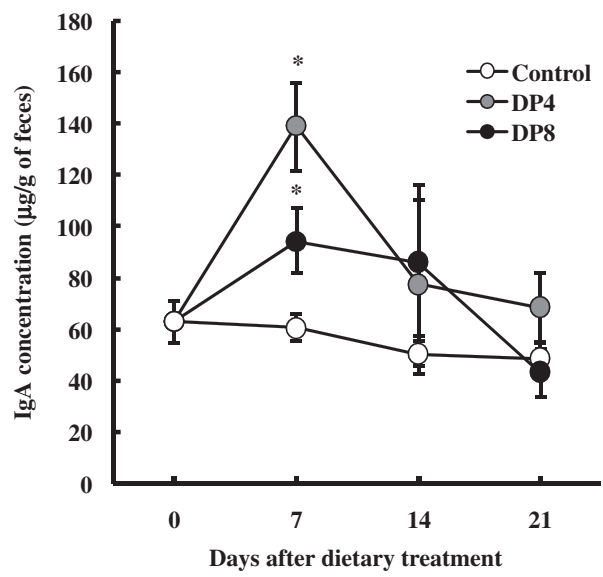

Fig. 3. Changes in the Fecal MPO Activity (a) and Fecal IgA Concentration (b) in Rats Fed the Respective Diets for $24 \mathrm{~d}$. Data are expressed as the mean $\pm \mathrm{SE}$ (control, $n=15$; DP4 and DP8, $n=10$ ). ${ }^{*} p<0.05 v s$. control.

of the dietary groups. However, the relative colon weight differed among the groups, being highest in the DP8 group, intermediate in the control group, and lowest in the DP4 group (Table 1). The colonic MPO activity was significantly lower in the DP4 group than in the control and DP8 groups. The cecal tissue weight was highest in the DP8 group, intermediate in the DP4 group and lowest in the control diet group. The weight of the cecal contents was significantly higher in the rats fed the DP4 and DP8 diets than in those fed the control diet, and a significant decline of the cecal $\mathrm{pH}$ value was apparent in the rats fed the DP4 and DP8 diets. The cecal concentrations of organic acids differed significantly among the groups, the concentrations of acetate, propionate and total SCFA being highest in the rats fed the DP4 diet. The concentrations of $n$-butyrate and succinate were higher in the rats fed the DP4 and DP8 diets than in those fed the control diet, while the lactate concentration was highest in the rats fed the DP8 diet (Table 1). The cecal concentrations of IgA and mucin were higher in the DP4 and DP8 dietary groups than in the control diet group, while the cecal lactobacilli count was significantly increased solely in the DP4 dietary group. Cecal bifidobacteria were detected in some of the rats fed the DP4 (6/10) and DP8 (5/10) diets, but not detected in the rats fed the control diet $(0 / 15)$.

\section{Discussion}

It is a prerequisite that the average severity of colonic inflammation among the dietary groups is comparable at the beginning of the dietary treatment when evaluating the effects of dietary factors on the healing stage of colitis. Saiki ${ }^{28)}$ and Wagner et al. ${ }^{29)}$ have shown in a human experiment that the stool level of MPO in patients with active inflammatory bowel disease was correlated with laboratory parameters and the endoscopic grade of inflammation. The present results also showed that the fecal MPO activity was correlated with that of the inflamed colonic tissues in rats with TNBS colitis. Accordingly, after colitis had been established, the rats were assigned to each dietary group on the basis of the severity of the fecal MPO activity.

Unlike the results from a previous study showing that both DP4 and DP8 had preventive effects against the development of TNBS-induced colitis in rats, ${ }^{7)}$ the present results clearly show that only DP4, but not DP8, ameliorated the healing process of TNBS-induced colitis when the dietary treatment was initiated $10 \mathrm{~d}$ after the induction of colitis. This ameliorating effect of DP4 was accompanied by higher cecal concentrations of SCFA, and propionate in particular, and by the cecal numbers of lactobacilli and bifidobacteria when compared with 
Table 1. Colonic and Cecal Variables in Rats with TNBS-Induced Colitis after Ingestion of the Respective Diets for $24 \mathrm{~d}$

\begin{tabular}{|c|c|c|c|}
\hline & Control & DP4 & DP8 \\
\hline \multicolumn{4}{|l|}{ Colon } \\
\hline Length, cm & $11.3 \pm 1.3$ & $11.7 \pm 0.4$ & $12.1 \pm 0.4$ \\
\hline Relative weight, $\mathrm{mg} / \mathrm{cm} \mathrm{c}$ & $120 \pm 7^{\mathrm{ab}}$ & $108 \pm 6^{\mathrm{a}}$ & $148 \pm 13^{\mathrm{b}}$ \\
\hline MPO activities, unit/g of colon & $8.1 \pm 1.4^{\mathrm{b}}$ & $3.7 \pm 0.9^{\mathrm{a}}$ & $7.4 \pm 1.5^{\mathrm{b}}$ \\
\hline \multicolumn{4}{|l|}{ Cecum } \\
\hline Tissue, $\mathrm{g}$ & $0.7 \pm 0.0^{\mathrm{a}}$ & $1.2 \pm 0.1^{\mathrm{b}}$ & $2.6 \pm 0.2^{\mathrm{c}}$ \\
\hline Contents ${ }^{1}, \mathrm{~g}$ & $2.0(1.3-2.8)$ & $3.7(2.6-5.5)^{*}$ & $3.1(0.5-4.3)^{*}$ \\
\hline $\mathrm{pH}$ & $7.6 \pm 0.0^{c}$ & $6.8 \pm 0.1^{\mathrm{b}}$ & $6.4 \pm 0.1^{\mathrm{a}}$ \\
\hline \multicolumn{4}{|l|}{ Organic acids, $\mu \mathrm{mol} / \mathrm{g}$ of wet contents } \\
\hline Acetate $^{1}$ & $47(23-55)$ & $75(42-102)^{*}$ & $54(20-132)$ \\
\hline Propionate $^{1}$ & $12(6-16)$ & $46(10-61)^{*}$ & $9(4-55)$ \\
\hline$n$-Butyrate & $7 \pm 3^{\mathrm{a}}$ & $25 \pm 3^{\mathrm{b}}$ & $20 \pm 4^{\mathrm{b}}$ \\
\hline Total SCFAs ${ }^{1,2}$ & $61(30-118)$ & $145(64-197)^{*}$ & $79(30-232)$ \\
\hline Lactate $^{1}$ & $0(0-1)$ & $0(0-21)$ & $9(0-40)^{*}$ \\
\hline Succinate $^{1}$ & $2(1-6)$ & $18(9-35)^{*}$ & $5(1-19)^{*}$ \\
\hline $\mathrm{IgA}, \mu \mathrm{g} / \mathrm{g}$ of wet contents & $46 \pm 8^{a}$ & $229 \pm 60^{\mathrm{b}}$ & $129 \pm 34^{\mathrm{b}}$ \\
\hline Mucin ${ }^{1}, \mu \mathrm{mol} / \mathrm{g}$ of wet contents & $0.3(0.2-0.7)$ & $0.5(0.4-0.7)^{*}$ & $1.3(0.5-2.6)^{*}$ \\
\hline Lactobacilli $^{1}, \times 10^{8}$ copies/g of wet contents & $0.9(0.2-2.6)$ & $3.5(0.2-123)^{*}$ & $1.7(0.2-3.4)$ \\
\hline Bifidobacteria $^{1}, \times 10^{7}$ copies $/ g$ of wet contents & $\mathrm{nd}^{4}$ & $23.1(6.8-619.7)(6)^{3, \dagger}$ & $0.5(1.9-2.8)(5)^{3}$ \\
\hline
\end{tabular}

Data are expressed as the mean $\pm \mathrm{SE}$ or median (range); control, $n=15$; DP4, $n=10$; DP8, $n=10$. Values not sharing a common superscript letter are significantly different when analyzed by the Tukey-Kramer test.

${ }^{1}$ Data were examined by Kruskal-Wallis one-way ANOVA, followed by the Kolmogorov-Smirnov two-sample test. ${ }^{*} p<0.05 v s$. control.

${ }^{2}$ Sum of acetate, propionate, and $n$-butyrate.

${ }^{3}$ Detected number of rats; ${ }^{\dagger} p<0.05 v s$. DP8 by the Mann-Whitney U-test.

${ }^{4}$ Not detected.

those of the control and DP-8 diets. The present study is, to our knowledge, the first to demonstrate an ameliorating effect of fructooligosaccharides (DP4) on colonic inflammation when the treatment was initiated after establishing colitis.

SCFAs, the predominant end-products of non-digestible carbohydrate fermentation in the colon, exert a variety of physiological effects. Inter alia, $n$-butyrate is the major energy source of colonocytes ${ }^{30)}$ and inhibits the activation of nuclear factor $-\kappa \mathrm{B}$ that encodes proteins playing important roles in immune response and inflammation. $^{31)}$ The physiological concentration of butyrate has also caused a significant increase in mucus secretion in the colonic lumen ${ }^{32)}$ that may serve as an intestinal barrier against bacterial and endotoxin translocation. The efficacy of butyrate enemas has been reported for patients with diversion colitis or distal ulcerative colitis. ${ }^{33,34)}$ Butzner et al. $^{35)}$ have shown that butyrate enema therapy stimulated mucosal repair in rat TNBS colitis, but Tarrerias et al. ${ }^{36)}$ have reported that a butyrate enema failed to decrease colonic hypersensitivity and inflammation. Despite the higher butyrate and mucin concentrations in the present study in the rats fed both the DP4 and DP8 diets, no effect on colonic inflammation was apparent in rats fed the DP8 diet. We therefore cannot ascribe the healing effect of DP4 solely to the higher butyrate concentration.

SCFAs, and particularly acetate and propionate, have recently been found to bind and activate G-proteincouple receptor 43 (GPR 43, also known as FFAR2) present mainly in neutrophils. ${ }^{37)}$ It has also been suggested that the stimulation of GPR43 by SCFAs could play a central role in the normal resolution of colonic inflammatory responses. ${ }^{38)}$ In this respect, it is notable that the cecal concentrations of acetate and propionate were much greater in rats fed the DP4 diet than in those fed the control and DP8 diets. It is therefore plausible to assume that, under the exper- imental conditions used in the present study, the higher concentrations of cecal propionate and acetate in the rats fed the DP4 diet might have been responsible for the reduction of colonic inflammation during the healing process of TNBS colitis.

Another possibility for the anti-inflammatory effects of DP4 may have been the increased numbers of cecal lactobacilli and bifidobacteria. Cherbut et $a .^{5)}$ have suggested that the capacity of fructooligosaccharides (virtually DP4) to increase the lactobacilli count was the main mechanism explaining their protective effect on colonic inflammation, rather than the increased SCFA production. Indeed, lactic acid bacteria have evoked a local immune stimulus to increase the levels of luminal secretory $\operatorname{Ig} \mathrm{A}^{39,40)}$ and anti-inflammatory cytokine-like IL-10. ${ }^{41)}$ Ingesting DP4 increased the cecal concentration of lactic acid-producing bacteria accompanying the increased cecal IgA concentration to the greater degree than that observed in the control and DP8 groups.

Despite the greater preventive effects shown by DP8 in the previous study, ${ }^{7)}$ the DP8 treatment failed to reduce, but rather aggravated colonic inflammation in the healing stage of colitis. The reason for this has not yet been fully elucidated, although it is well known that administering TNBS altered the microflora, decreasing lactobacilli and increasing gram-negative bacilli in the rat cecum. ${ }^{42,43)}$ The bacterial capacity to ferment ingested SIF under such conditions might be considerably compromised when compared with normal conditions just before the induction of colitis. Our previous study has clearly shown that the beneficial effects of DP4 and DP8 on cecal SCFAs, lactate, $\mathrm{pH}$ value, mucin and $\operatorname{IgA}$ were totally abolished by $10 \mathrm{~d}$ post-TNBS administration, even when the treatment started before the induction of colitis. ${ }^{7)}$ However, the importance of the substrate size (DP) in the fermentation of fructans has been reported in a previous study, indicating that 1-kestose and nystose were directly incorporated into 
Lactobacillus paracasei without any hydrolysis and were rapidly fermented. ${ }^{44)}$ Since DP4 mainly consisted of 1-kestose and nystose, these fractions might be preferable as fermentation substrates by lactobacilli, rather than DP8 with higher DP. Differences in the fermentability by lactobacilli between DP4 and DP8 in the damaged condition might therefore explain the different concentrations of cecal acetate and propionate, and the numbers of lactic acid-producing bacteria after the prolonged treatment of these SIFs for $24 \mathrm{~d}$, resulting in the different outcomes of their anti-inflammatory effects.

Both DP4 and DP8 induced a transient increase in fecal MPO activities during the initial stage of 7-14 d after the dietary treatment, although the reason for this remains unclear. However, TNBS administration per se has promoted the proliferation of gram-negative bacilli during the acute phase of colitis. ${ }^{42,43)}$ It is therefore reasonable to assume that expansion of the pool size of the cecal endotoxin may result in transient exacerbation of the colonic inflammation. ${ }^{43)}$ However, DP4 is the preferred substrate for lactobacilli, rather than DP8, so prolonged ingestion of DP4 may gradually reduce the load from gram-negative bacilli by the shorter period of time than that possible with DP8.

In conclusion, DP4 alone, but not DP8 ameliorated the healing process of TNBS-induced colitis, even when the treatment was started after the induction of colitis. The higher concentration of cecal propionate and the stimulated proliferation of lactic acid-producing bacteria resulting from DP4 ingestion might be closely associated with the ameliorating effect on the healing process for TNBS colitis in rats.

\section{References}

1) Newman B and Siminovitch KA, Curr. Opin. Gastroenterol., 21, 401-407 (2005).

2) Sanderson IR, J. Nutr., 137, 2557S-2562S (2007).

3) Hallert C, Bjorck I, Nyman M, Pousette A, Granno C, and Svensson H, Inflamm. Bowel. Dis., 9, 116-121 (2003).

4) Campbell JM, Fahey GC, and Wolf BW, J. Nutr., 127, 130-136 (1997).

5) Cherbut C, Michel C, and Lecannu G, J. Nutr., 133, 21-27 (2003).

6) Peran L, Sierra S, Comalada M, Lara-Villoslada F, Bailon E, Nieto A, Concha A, Olivares M, Zarzuelo A, Xaus J, and Gálvez J, Br. J. Nutr., 97, 96-103 (2007).

7) Ito $H$, Tanabe $H$, Kawagishi $H$, Tadashi $W$, Yasuhiko $T$, Sugiyama K, Kiriyama S, and Morita T, Dig. Dis. Sci., 54, 2100-2108 (2009).

8) Gill HS, Best Pract. Res. Clin. Gastroenterol., 17, 755-773 (2003).

9) Llopis M, Antolin M, Guarner F, Salas A, and Malagelada JR, Gut, 54, 955-959 (2005).

10) Lara-Villoslada F, de Haro O, Camuesco D, Comalada M, Velasco J, Zarzuelo A, Xaus J, and Galvez J, Eur. J. Nutr., 45, 418-425 (2006).

11) Lamine F, Eutamene H, Fioramonti J, Bueno L, and Theodorou V, Scand. J. Gastroenterol., 39, 1250-1258 (2004).

12) Daddaoua A, Puerta V, Requena P, Martinez-Ferez A, Guadix E, de Medina FS, Zarzuelo A, Suarez MD, Boza JJ, and Martinez-Augustin O, J. Nutr., 136, 672-676 (2006).

13) Kennedy RJ, Hoper M, Deodhar K, Kirk SJ, and Gardiner KR, Scand. J. Gastroenterol., 35, 1266-1271 (2000).
14) Morris GP, Beck PL, Herridge MS, Depew WT, Szewczuk MR, and Wallace JL, Gastroenterology, 96, 795-803 (1989).

15) Yamada Y, Marshall S, Specian RD, and Grisham MB, Gastroenterology, 102, 1524-1534 (1992).

16) Wallace JL, McKnight W, Asfaha S, and Liu DY, Am. J. Physiol., 274, G802-G808 (1998).

17) Holma R, Juvonen P, Asmawi MZ, Vapaatalo H, and Korpela R, Scand. J. Gastroenterol., 37, 1042-1047 (2002).

18) Sun FF, Lai PS, Yue G, Yin K, Nagele RG, Tong DM, Krzesicki RF, Chin JE, and Wong PY, Inflammation, 25, 33-45 (2001).

19) Ito $H$, Wada $T$, Ohguchi $M$, Sugiyama K, Kiriyama $S$, and Morita T, J. Food Sci., 73, H36-H41 (2008).

20) American Institute of Nutrition, J. Nutr., 107, 1340-1348 (1977).

21) Morita $T$, Kasaoka S, Ohhashi A, Ikai M, Numasaki $Y$, and Kiriyama S, J. Nutr., 128, 1156-1164 (1998).

22) Morita $T$, Tanabe $H$, Takahashi $K$, and Sugiyama $K$, J. Gastroenterol. Hepatol., 19, 303-313 (2004).

23) Grewal HM, Karlsen TH, Vetvik H, Ahren C, Gjessing HK, Sommerfelt H, and Haneberg B, J. Immunol. Methods, 26, 5362 (2000).

24) Bovee-Oudenhoven IM, Termont DS, Heidt PJ, and van der Meer R, Gut, 40, 497-504 (1997).

25) Crowther RS and Wetmore RF, Anal. Biochem., 163, 170-174 (1987).

26) Rinttila T, Kassinen A, Malinen E, Krogius L, and Palva A, J. Appl. Microbiol., 97, 1166-1177 (2004).

27) Byun R, Nadkarni MA, Chhour KL, Martin FE, Jacques NA, and Hunter N, J. Clin. Microbiol., 42, 3128-3136 (2004).

28) Saiki T, Kurume Med. J., 45, 69-73 (1998).

29) Wagner M, Peterson CG, Ridefelt $P$, Sangfelt $P$, and Carlson M, World J. Gastroenterol., 14, 5584-5589 (2008).

30) Roediger WE, Gut, 21, 793-798 (1980).

31) Segain JP, Raingeard de la Bletiere D, Bourreille A, Leray V, Gervois N, Rosales C, Ferrier L, Bonnet C, Blottiere HM, and Galmiche JP, Gut, 47, 397-403 (2000).

32) Barcelo A, Claustre J, Moro F, Chayvialle JA, Cuber JC, and Plaisancie P, Gut, 46, 218-224 (2000).

33) Vernia P, Marcheggiano A, Caprilli R, Frieri G, Corrao G, Valpiani D, Di Paolo MC, Paoluzi P, and Torsoli A, Aliment. Pharmacol. Ther., 9, 309-313 (1995).

34) Luhrs H, Gerke T, Muller JG, Melcher R, Schauber J, Boxberge F, Scheppach W, and Menzel T, Scand. J. Gastroenterol., 37, 458-466 (2002).

35) Butzner JD, Parmar R, Bell CJ, and Dalal V, Gut, 38, 568-573 (1996).

36) Tarrerias AL, Millecamps M, Alloui A, Beaughard C, Kemeny JL, Bourdu S, Bommelaer G, Eschalier A, Dapoigny M, and Ardid D, Pain, 100, 91-97 (2002).

37) Brown AJ, Goldsworthy SM, Barnes AA, Eilert MM, Tcheang L, Daniels D, Muir AI, Wigglesworth MJ, Kinghorn I, Fraser NJ, Pike NB, Strum JC, Steplewski KM, Murdock PR, Holder JC, Marshall FH, Szekeres PG, Wilson S, Ignar DM, Foord SM, Wise A, and Dowell SJ, J. Biol. Chem., 278, 11312-11319 (2003).

38) Maslowski KM, Vieira AT, Ng A, Kranich J, Sierro F, Yu D, Schilter HC, Rolph MS, Mackay F, Artis D, Xavier RJ, Teixeira MM, and Mackay CR, Nature, 461, 1282-1286 (2009).

39) Takahashi T, Oka T, Iwana H, Kuwata T, and Yamamoto Y, Biosci. Biotechnol. Biochem., 57, 1557-1560 (1993).

40) Takahashi T, Nakagawa E, Nara T, Yajima T, and Kuwata T, Biosci. Biotechnol. Biochem., 62, 10-15 (1998).

41) Steidler L, Hans W, Schotte L, Neirynck S, Obermeier F, Falk W, Fiers W, and Remaut E, Science, 289, 1352-1355 (2000).

42) Gardiner KR, Erwin PJ, Anderson NH, Barr JG, Halliday MI, and Rowlands BJ, Br. J. Surg., 80, 512-516 (1993).

43) Gardiner KR, Erwin PJ, Anderson NH, McCaigue MD, Halliday MI, and Rowlands BJ, Br. J. Surg., 82, 469-472 (1995).

44) Kaplan H and Hutkins RW, Appl. Environ. Microbiol., 69, 2217-2222 (2003). 